\title{
A Grid-Connected Multilevel Current Source Inverter and Its Protection for Grid-Disconnection
}

\author{
Nimrod Vázquez, ${ }^{1,2}$ Luz del Carmen García, ${ }^{1}$ Claudia Hernández, ${ }^{1}$ Eslí Vázquez, ${ }^{3}$ \\ Héctor López, ${ }^{1}$ Ilse Cervantes, ${ }^{2}$ and Juan Iturria ${ }^{4}$ \\ ${ }^{1}$ Electronics Engineering Department, Technological Institute of Celaya, 38010 Celaya, GTO, Mexico \\ ${ }^{2}$ Applied Mathematics Division, Potosino Institute of Scientific and Technological Research, 78216 San Luis Potosi, SLP, Mexico \\ ${ }^{3}$ Engineering Faculty, Veracruz University, 94294 Boca del Rio, VER, Mexico \\ ${ }^{4}$ CEO, Hawk Diverse Trailers, 38000 Celaya, GTO, Mexico
}

Correspondence should be addressed to Nimrod Vázquez; n.vazquez@ieee.org

Received 4 November 2012; Revised 7 February 2013; Accepted 23 April 2013

Academic Editor: Tapas Mallick

Copyright (C) 2013 Nimrod Vázquez et al. This is an open access article distributed under the Creative Commons Attribution License, which permits unrestricted use, distribution, and reproduction in any medium, provided the original work is properly cited.

\begin{abstract}
Traditionally DC-AC converters are considered with voltage source inverters (VSI); although less studied and discussed, it has started recently to be used current source inverters (CSI). Another possibility for DC/AC conversion is the multilevel configuration. This paper shows experimental operation and simulation analysis of a grid-connected multilevel current source inverter (MCSI), which includes a circuit for equipment safety reasons due to grid disconnections.
\end{abstract}

\section{Introduction}

Since fossil fuels are depleting day by day, research has started to focus on different alternatives in order to fulfill the required energy around the world. Nowadays, renewable energy is becoming more important. There exist some applications of renewable energy which employ hundreds of MW (high power), and there are also some of those, which uses hundreds of few $\mathrm{W}$ (low power). Applications may also be classified depending on if they are connected to the grid or not, and also it is well known as cogeneration and stand-alone systems.

Grid connected systems deliver the maximum obtainable power from the photovoltaic (PV) and/or wind system to the AC mains [1]; since energy supply changes according to weather conditions, then possible amount of released energy also changes. Algorithms such as improved perturbation and observation method [2], sliding mode observer technique [3], and some others [4-8] are employed to seek the maximum power point (MPP).

For increasing system efficiency, low voltages are used not only in solar cell arrays [9], but also in some wind systems. Hence, boosting type converters are required for these systems. Different topologies which provide current to the AC mains are shown in Figures 1 and 2, based on VSI and CSI respectively.

A two-stage topology is illustrated in Figure 1(a): a DC/DC boost converter and a DC/AC converter [4]. For increasing input voltage, a DC/DC converter, which allows interaction to the AC mains, not only is used for constant output voltage but also is employed in order to perform the MPP, while inverter stage delivers a sinusoidal current to the utility line. Converter as illustrated in Figure 1(b) also includes two stages: multiple isolated DC/DC converters and a multilevel inverter [9]; first stage is mainly used for isolation purposes and the second one is used for providing sinusoidal current to the AC mains. Converter addressed in Figure 1(c) has also two stages: a DC/DC boost converter and a nontraditional multilevel inverter [10]; first stage is mainly used for increasing the input voltage, and the next one is used to provide sinusoidal current to the AC mains. Some other schemes are found in the literature [11-14].

Systems, which combine the power from two or more sources, are normally found in the literature [15-21]. Some authors [15] have suggested a converter which is able to obtain 


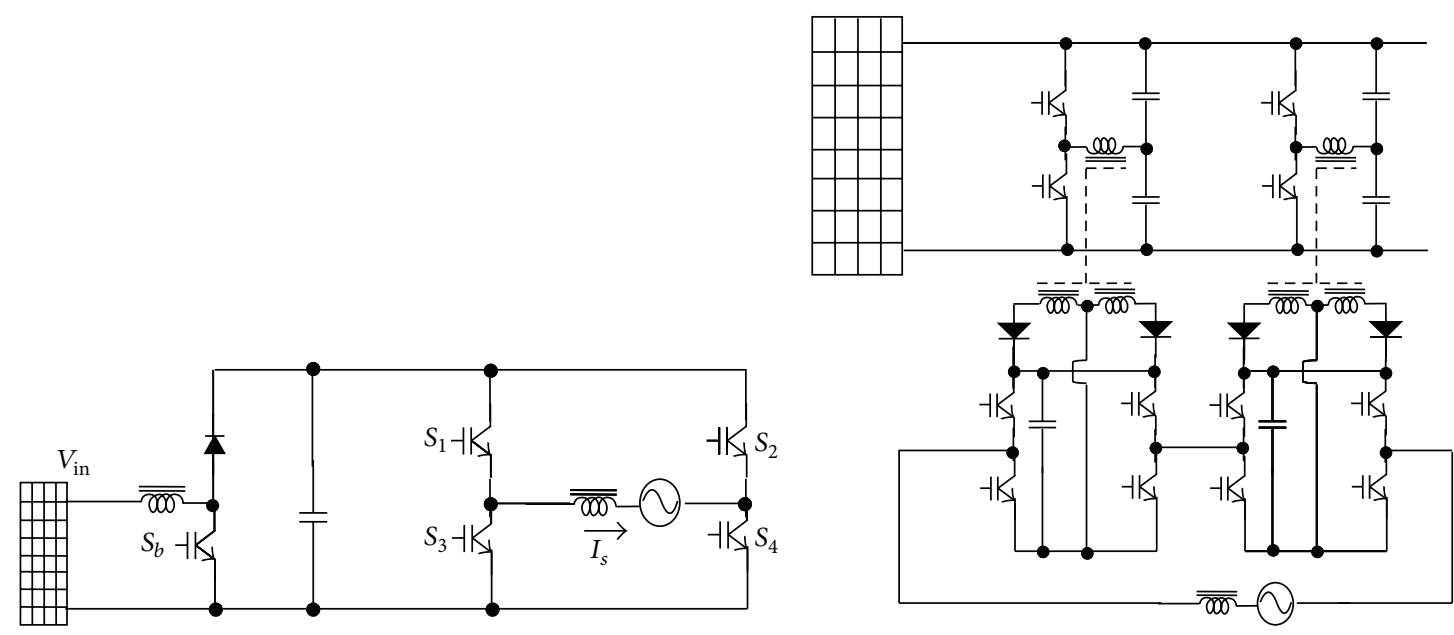

(a) $\mathrm{Dc} / \mathrm{dc}$ converter and inverter

(b) Multiple dc/dc converters and multilevel inverter

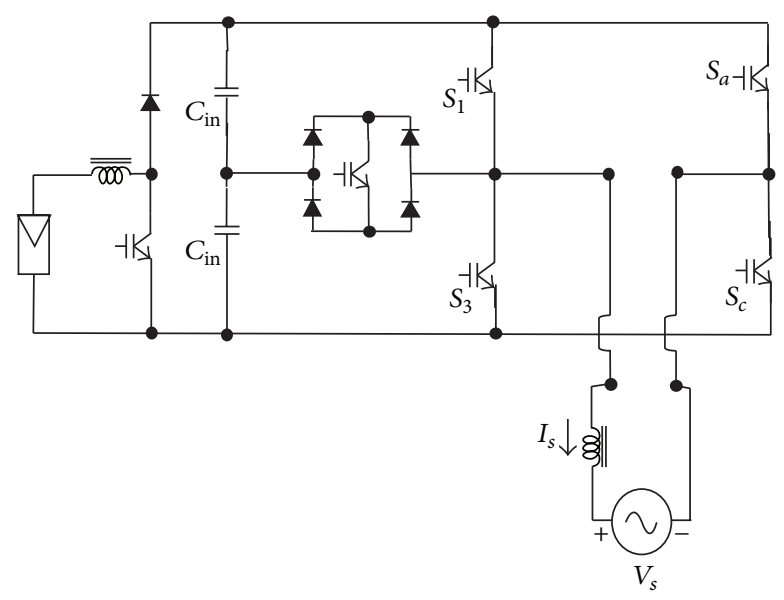

(c) DC/DC boost converter and multilevel inverter

FIgURE 1: Topologies to inject current to the ac mains based on VSI.

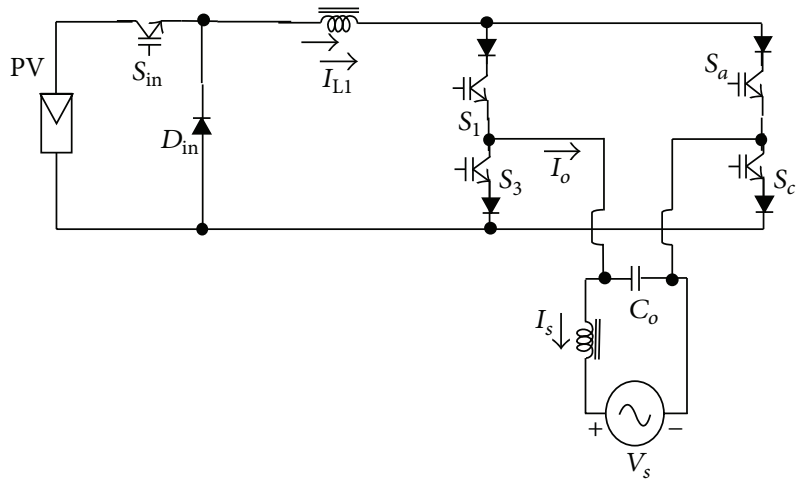

(a) Buck converter and CSI converter

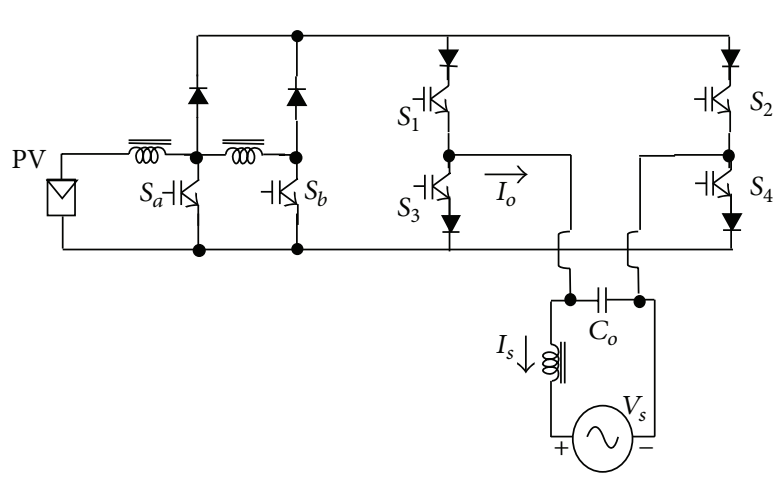

(b) Multilevel scheme based on Boost converter and CSI converter

FIgURE 2: Topologies to inject current to the ac mains based on CSI.

energy from a PV array and the utility; however, for this particular case, there is not energy injected to the AC mains. Some others [16] have proposed a series of DC/DC converters connected when multiple photovoltaic panels are employed, a single converter for each panel, and also a DC/AC converter is taken into account. In [17] has been proposed a system which considers photovoltaic panels and a wind turbine as main inputs, the photovoltaic voltage is higher than the output voltage, and the wind turbine voltage is lower than the output voltage. 
Converters based on CSI, which are shown in Figure 2, are able to handle photovoltaic arrays [22-25], with the aid of DC/DC converters. Both buck and inverter are used to inject energy to the AC mains [22] as illustrated in Figure 2(a). For this topology in particular the input has to have high voltage. Figure 2(b) illustrates the use of DC/DC boost converter in order to produce a multilevel output [23]; the CSI is operated at low frequency, as a polarity inverter.

Some multilevel CSI, which are not applied to PV systems, are for general purpose $[26,27]$.

A comparative performance evaluation for PV system between VSI and CSI is shown in the literature [25]. Comparison is made under short-circuit fault conditions, and it demonstrates how CSI offers a better solution. However, grid disconnection is not consider, into account; as it will be shown next in this paper, this may cause damage in CSI if a protection circuit is not considered.

This paper discusses about a grid connected CSI of multilevel type, which combines CSI and multilevel converter features. Inverter topology is already found in the literature [27]; however, it did not consider grid connection. This converter is simple, and it uses fewer or equal amount of semiconductors than the multilevel CSI described in the literature [25-27]. The important part of this proposal is to include the protection circuit for grid disconnection, which differs from islanding protection. A CSI under grid connection must include this type of protection as will be shown.

The paper is organized as follows: the proposed converter is addressed in Section 2 it includes not only operation and waveforms but also implementation details; simulation and experimental results are discussed in Section 3, and finally some conclusions are given.

\section{Proposed Grid Connected Multilevel Current Source Inverter}

The proposed idea consists of a CSI, but a multilevel type allows producing an output current with a lower harmonic content with a relatively low semiconductors switching frequency. This converter injects current to the AC mains in parallel connection. A circuit for grid disconnection is considered for safety reasons. This multilevel converter topology is illustrated in Figure 3.

2.1. Operation of the Converter. For an easy explanation of how multilevel CSI operates, the input current is considered constant (large inductors); when switches $S_{1}, S_{2}$, and $S_{3}$ are turned on, the rest of switches are turned off; in fact the control signal of $S_{1}$ is exactly the opposite of $S_{a}$ and the same for the others switches. In practice there exist a small overlapping in the control signals $S_{1}$ and $S_{a}$, this is because always a current path must be provided to the inductors in order to avoid the semiconductor damage.

Current generated by the MCSI is shown in Figure 4 . These waveforms are at low frequency, and only the positive

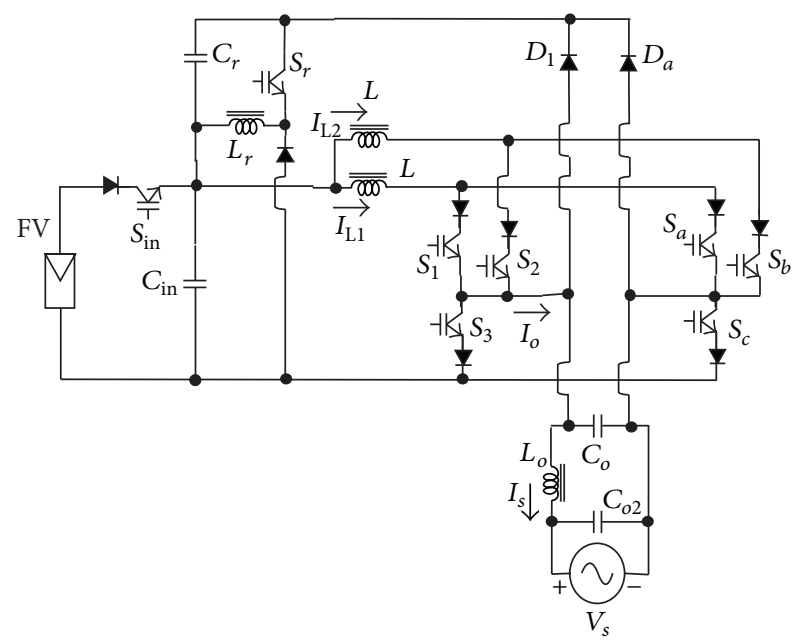

FIGURE 3: Proposed grid connected multilevel current source inverter.

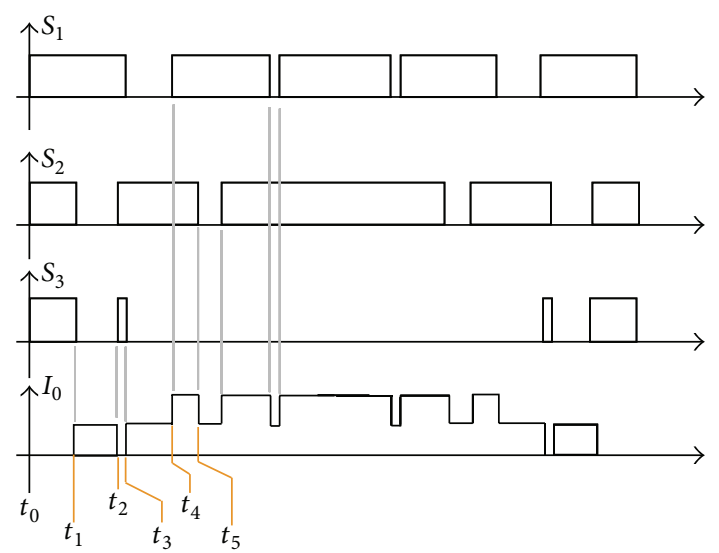

FIGURE 4: Control signals and output current. Top to down: control signal of $S_{1}$, control signal of $S_{3}$, control signal of $S_{2}$, and output current.

semicycle is shown in order to illustrate the behavior. Control signals for switches $S_{1}, S_{2}$, and $S_{3}$ are also included. According to this Figure 4, the converter operates as follows:

(1) During $t_{0}-t_{1}, S_{1}, S_{2}$, and $S_{3}$ are turned on, the equivalent subcircuit is shown in Figure 5(a), then zero current is injected (also a zero current may be produced when $S_{1}, S_{2}$ and $S_{3}$ are turned off).

(2) During $t_{1}-t_{2}, S_{1}$ is maintained on, $S_{2}$ and $S_{3}$ are turned off, the equivalent subcircuit is shown in Figure 5(b), and then a positive current is delivered.

(3) During $t_{2}-t_{3}$. The same switches state used during $t_{0}-t_{1}$ is considered during this stage; then a zero current output is obtained. 
TABLE 1: Switching states of the converter.

\begin{tabular}{lccc}
\hline Output current & \multicolumn{3}{c}{ Switches } \\
& $S_{1}$ & $S_{2}$ & $S_{3}$ \\
\hline \multirow{2}{*}{ Zero } & 1 & 1 & 1 \\
& 0 & 0 & 0 \\
Positive & 1 & 0 & 0 \\
Double positive & 0 & 1 & 0 \\
Negative & 1 & 1 & 0 \\
Double negative & 0 & 1 & 1 \\
"1" means "on." & 1 & 0 & 1 \\
"0" means "off." & 0 & 0 & 1 \\
\hline
\end{tabular}

(4) During $t_{3}-t_{4}$, a positive current is injected to the load, but in this case the other combination is used. $S_{2}$ is turned on; $S_{1}$ and $S_{3}$ are turned off.

(5) During $t_{4}-t_{5}, S_{1}$ and $S_{2}$ are turned on, $S_{3}$ is turned off, the equivalent subcircuit is shown in Figure 5(c), and then a double magnitude of positive current is obtained.

(6) After $t_{5}$, during the rest of time, the converter operation is similar to that mentioned previously. In Table 1 summarized the different switching states to produce the required output current.

2.2. Circuit Protection for Grid Disconnection. An important part in this proposal is the protection circuit for grid disconnection. Elements for this circuit are a couple of diodes $D_{1}, D_{a}$, a capacitor $C_{r}$, and a dc/dc buck-boost converter composed by $S_{r}, L_{r}$ and its diode (Figure 3 ).

The inverter may be described mathematically as a current source when it is connected to the ac mains in parallel; if grid disconnection occurs, for any circumstance (break protection, utility failure), an overvoltage will be generated, which certainly will damage not only the converter but also the other connected devices to it. For avoiding this situation, a current path must be provided to the current source, which prevents any damage to the system.

When grid disconnection occurs, the current of the inverter will charge the output capacitor, and then diode $D_{1}$ or $D_{a}$ (depending on the AC mains semicycle) is able to conduce by charging the capacitor $C_{r}$. Figure 6 illustrates the subcircuit for the positive semicycle, by the time when diode $D_{1}$ start to conduce, then the capacitor voltage $C_{r}$ will be increased; once the capacitor voltage increment is detected, the auxiliary switch $\left(S_{\text {in }}\right)$ is turned off, and this will turn off the system; however the inductor is still transferring remaining energy to the capacitor $C_{r}$ (Figure 6(b)). It should be noticed that, under normal condition $S_{\text {in }}$ must be turned on.

Once, system starts to operate normally (after reconnection and detection of AC mains), the DC/DC buck-boost converter will recover the stored energy in capacitor $C_{r}$ at the input of the multilevel inverter by delivering energy to the capacitor $C_{\text {in }}$, then $S_{r}$ will be commuted until the capacitor reach its steady-state voltage.

2.3. Controlling the System. The proposed power converter controller is shown in Figure 7. It is composed by a voltage detector, a PLL, a MPP tracker, and a current controller with its multilevel modulation technique.

Voltage detector is used in order to realize; if a detected grid disconnection occurs, during voltage increment, the switch $S_{\text {in }}$ is turned off, which will assure a proper system operation. It is important to notice that grid voltage variation may occurs, because of this not any voltage increment should be considered as a grid disconnection; according to standard IEEE 929, a failure must be considered if the AC mains are $10 \%$ above its nominal value, which is evaluated as criteria for establishing that the system have failed.

PLL circuit is used to synchronize the injected current with the AC mains, this is necessary for delivering only real power to the AC mains; this means that current must be in phase with the AC mains.

For guaranty multilevel inverter operation not only PWM and current controller are used, but also the inductor current is balanced. For accomplishing this, switching state redundancy of the multilevel converter has to be taken into account; the technique is implemented by alternating both combinations in steady state and a simple controller, which is employed in order to regulate the inductor currents due to current unbalance, caused due to parasitic elements or disturbances in the system [27].

Waveforms of the PWM method employed at the inverter are shown in Figure 8; both two triangular carriers and a rectified reference signal are employed. Control signals for switches are obtained not only by comparing the carriers with the reference [27] but also by considering the AC mains semicycle and the information shown in Table 1; it is important to include the overlapping of switches control signal in order to assure the inductors current continuity.

2.4. Converter Gain. For carrying the analysis out, it is considered not only an averaged method but also that switching frequency is higher than the output voltage frequency. Then, the multilevel CSI is obtained as follows:

$$
I_{\mathrm{op}}=(n-1) M I_{L}
$$

where $I_{\mathrm{op}}$ is the amplitude of the average output current; $I_{L}$ is the inductor current; $M$ is the modulation index; and $n$ is the inverter output level.

By neglecting losses, we are able to make equal the input power and output power as follows:

$$
\begin{gathered}
P_{\text {in }}=P_{o}, \\
(n-1) I_{L} V_{\text {in }}=\frac{V_{\mathrm{op}} I_{\mathrm{op}}}{2},
\end{gathered}
$$




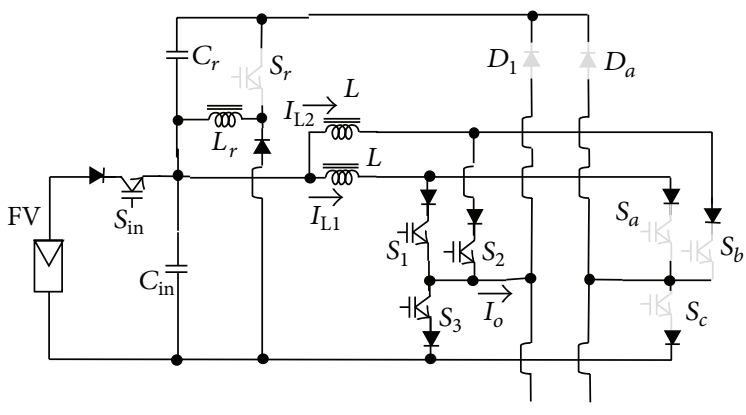

(a)

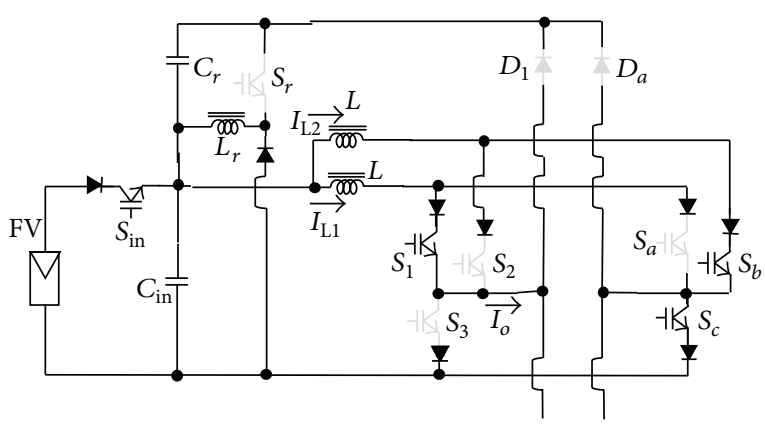

(b)

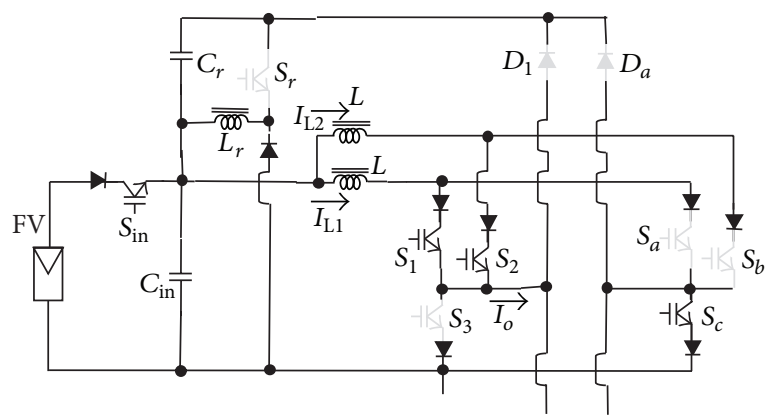

(c)

FIgURE 5: Subcircuits of the proposed multilevel CSI. (a) Subcircuit for zero current. (b) Subcircuit for positive current. (c) Subcircuit for double positive current.

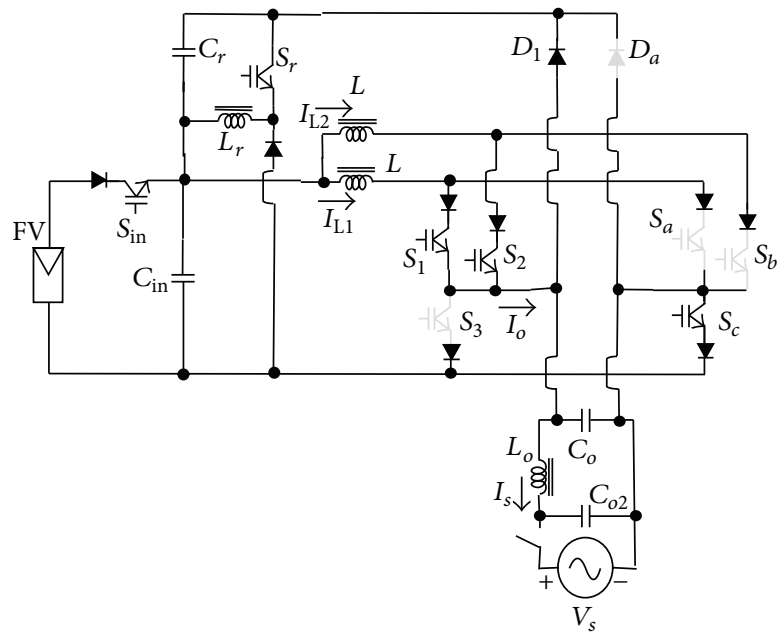

(a)

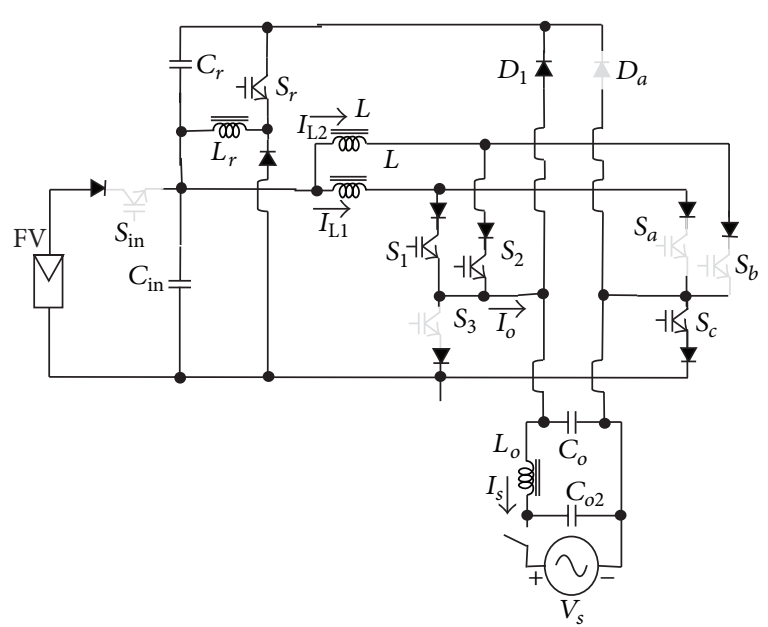

(b)

FIGURE 6: Subcircuit when the protection circuit is operating for positive semicycle.

where $P_{o}$ is the output power, $P_{\text {in }}$ is the input power, $V_{\text {in }}$ is the input voltage, $V_{\mathrm{op}}$ is the peak of the output voltage.

Expressions (1) and (2) lead us to

$$
\frac{V_{\mathrm{op}}}{V_{\text {in }}}=\frac{2}{M} \text {. }
$$

Voltage graph and current gain are shown in Figure 9, with $n=3$; for a three-level inverter, it should be noticed that with $M=1$ the current and voltage gain is equal to two in both; this means that the inductors current contribution is optimal, but the boosting function is lower. This graph also shows the CSI boosting capability, which is not found in the VSI; actually it is a bucking system, essential feature in PV applications.

2.5. Passive Elements Design. For having good converter operation the DC link inductor $(L)$ must be large, this guaranties a low harmonic distortion at the output. Let us 


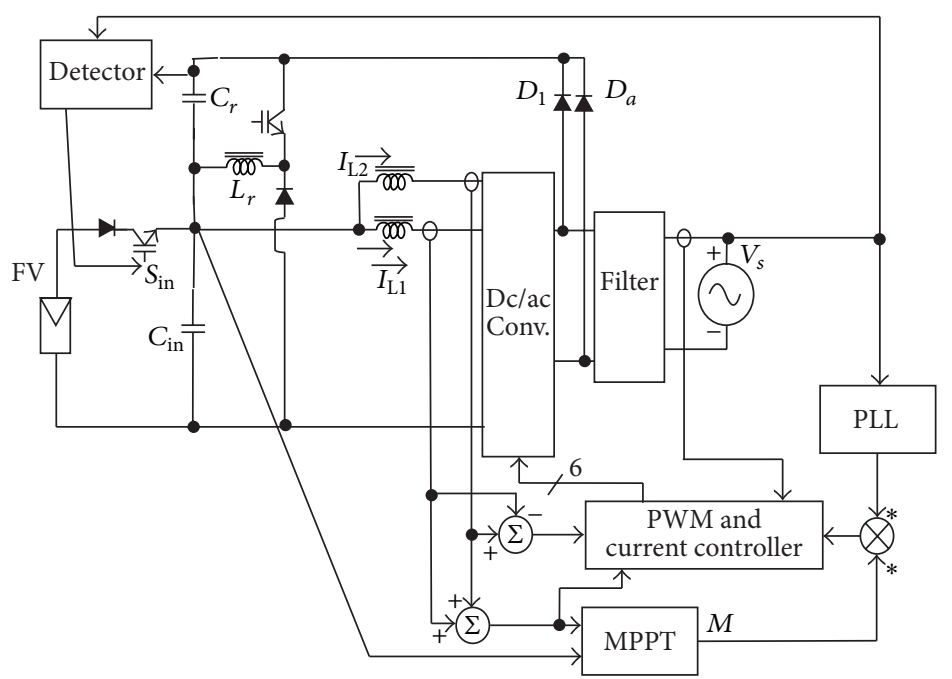

FIgURE 7: Controller of the system.
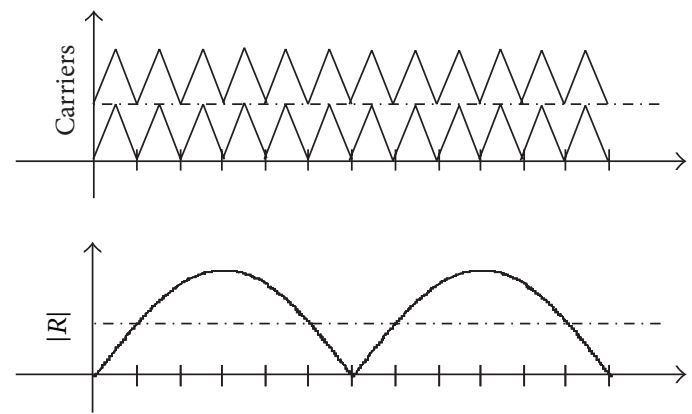

FIGURE 8: Waveforms of the PWM controller.

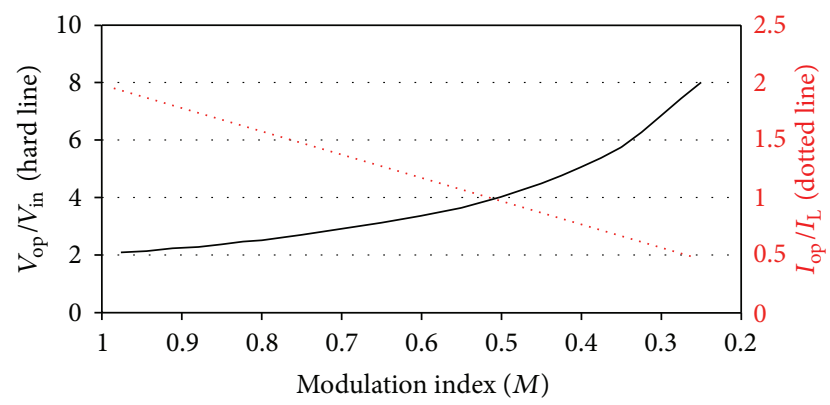

FIgURE 9: Gain graphs versus modulation index.

consider that the inductor keeps energy stored, and the required time to be discharged $L$ (just in case of an input voltage failure occurs) may be obtained according to

$$
L=\frac{2\left(P_{o} / 2\right) \Delta_{t}}{I_{L}^{2}},
$$

where $\Delta_{t}$ is the discharging time.

Considering next values: $P_{o}=100 \mathrm{~W}, I_{L}=500 \mathrm{~mA}$ and $\Delta_{t}=1 \mathrm{~ms}$ is obtained $L=400 \mathrm{mH}$, which allows a small current ripple at the input current in each inductor.
The output current filter may easily be designed by choosing both a desired filter corner frequency and a small inductor value (one freedom degree). Once this established, the output capacitor may be estimated by

$$
C_{o}=\frac{1}{L_{o}\left(2 \pi f_{c}\right)^{2}},
$$

where $L_{o}$ is the output inductor, which is chosen to be small; $f_{c}$ is the corner frequency of the filter.

Considering $f_{c}=5 \mathrm{KHz}, L_{o}=500 \mu \mathrm{H}$ is obtained $C_{o}=$ $2 \mu \mathrm{F}$.

For preventing grid disconnection, the capacitor $C_{r}$ must be designed and take a special value, which is chosen in order to guaranty the maximum energy stored by the inductors. However, it is important to set a limit to the capacitor voltage, which will avoid any damage not only to semiconductor but also to devices connected with the inverter. Capacitor may be calculated by:

$$
C_{r}=\frac{2 P_{o} \Delta_{t}}{V_{c}^{2}-V_{c_{o}}^{2}},
$$

where $V_{c}$ is maximum capacitor voltage, $V_{c_{o}}$ is the initial capacitor voltage.

Considering next values: $V_{c}=115 \mathrm{~V}, V_{c_{0}}=85 \mathrm{~V}, P_{o}=$ $100 \mathrm{~W}$, and $\Delta_{t}=1 \mathrm{~ms}$, the obtained capacitor is $C_{r}=33 \mu \mathrm{F}$.

When grid disconnection occurs, $C_{r}$ value establishes the detection delay, which has to have a minimum time of $1 \mathrm{~ms}$, according to design procedure with (6). While capacitor voltage is used for detecting this failure; notice that not only the detection delay changes but also the energy delivered by the CSI is variable due to the MPP of the PV.

CSI energy is delivered to the capacitor $C_{r}$, at the grid disconnection. If PV (energy source) is not disconnected then its delivered energy to this capacitor, would increase its voltage until its destruction, because of this reason, it is important to turn off the switch $S_{\text {in }}$ at the grid disconnection. 


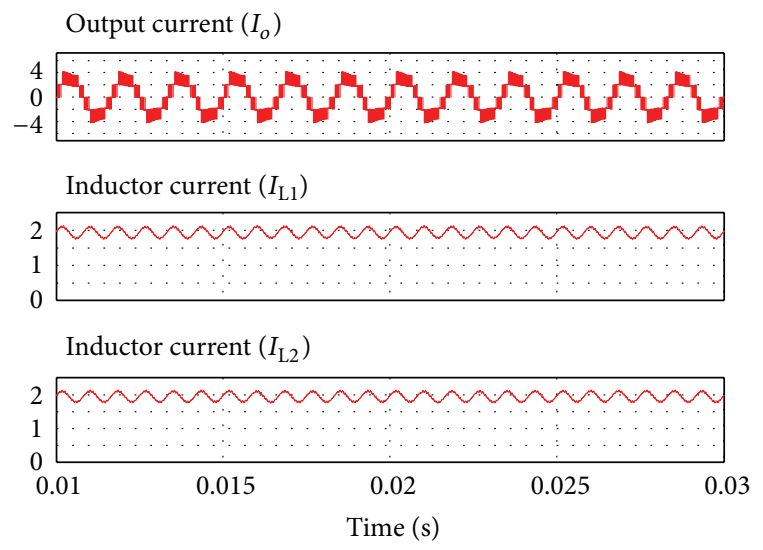

FIGURE 10: Steady-state operation of multilevel output current and inductors current. Top to bottom: multilevel output current $\left(I_{o}\right.$, $2 \mathrm{~A} /$ div $)$, inductor current $\left(I_{L 1}, 1 \mathrm{~A} /\right.$ div $)$.
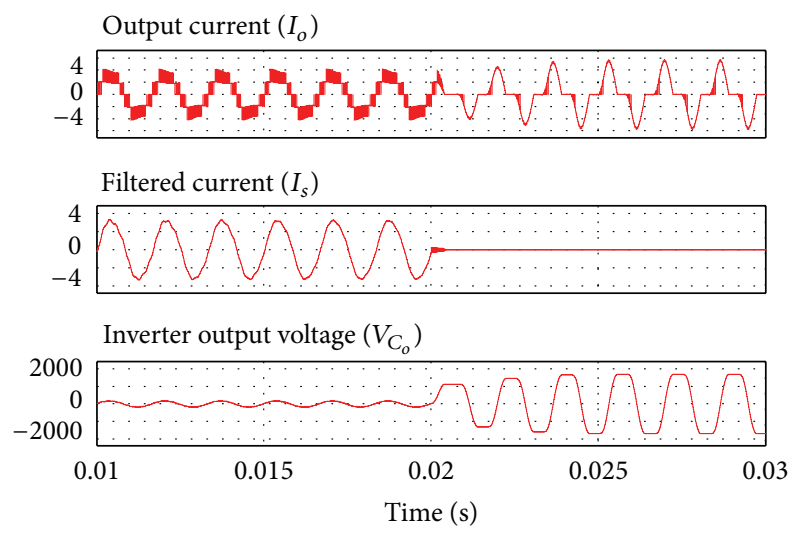

FIGURE 11: Operation of the system under a grid disconnection without the protection circuit. Top to bottom: output current $\left(I_{o}\right.$, $2 \mathrm{~A} / \mathrm{div})$, filtered current $\left(I_{s}, 2 \mathrm{~A} / \mathrm{div}\right)$, and Inverter output voltage $\left(V_{C_{o}}, 1000 \mathrm{~V} / \mathrm{div}\right)$.

\section{Simulation and Experimental Results}

The functionality of the system was not only mathematically simulated but also an experimental prototype was built, so that the proposed idea was validated.

Numerical simulations, shown through Figures 10 to 12 , were made at $600 \mathrm{~Hz}$ with an inductor of $40 \mathrm{mH}$ due to the simulator time response. Figure 10 shows not only the inductors currents but also the output current with a modulation index of 0.82 , it should be noticed that they are well balanced.

System performance under grid disconnection without the circuit protection is illustrated in Figure 11, where output current, filtered current and the capacitor $C_{o}$ voltage are shown. It is easily seen that, when the AC mains is disconnected, the capacitor voltage increases higher than $1000 \mathrm{~V}$, this would certainly causes damage to any circuit; therefore it is necessary the circuit protection.

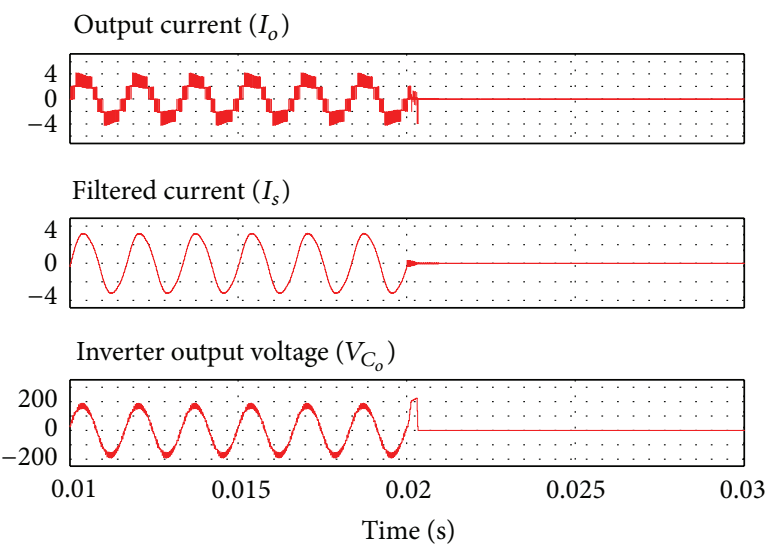

FIGURE 12: Operation of the system under a grid disconnection with the protection circuit. Top to bottom: output current $\left(I_{o}\right.$, $2 \mathrm{~A} / \mathrm{div})$, Filtered current $\left(I_{s}, 2 \mathrm{~A} / \mathrm{div}\right)$, and inverter output voltage $\left(V_{C_{o}}, 100 \mathrm{~V} /\right.$ div $)$.

Without protection for the grid disconnection, CSI energy is delivered to the output capacitor $C_{o}$, and then the capacitor increases its voltage until its destruction, as shown in Figure 10. Capacitor voltage reaches more than $1000 \mathrm{~V}$ in less time that a half semicycle of the AC mains.

It is also noticed that after failure, current is distorted and voltage is out of phase with respect to current; while current has zero value at certain times, the output capacitor voltage remains flat at this condition; however, this evolution in a the experimental prototype will not happen, because inverter damage occurs first.

A test for the system was carried out under grid disconnection, where the protection circuit was included, as it is shown in Figure 12. The output voltage for capacitor $C_{o}$ increases when the grid is disconnected, until then diode $D_{1}$ starts to conduce, after the system shutdown is made. The Figure shows output voltage, output current, and filtered current and capacitor $C_{o}$ voltage. It is clearly seen that the proposed scheme effectively avoids the system failure under a grid disconnection.

Figures 13-16 show experimental results: some of them are in steady-state, but some other were made to illustrated the operation of system under transitory. Input inductors are of $400 \mathrm{mH}$ and switching devices are IRG4PC40. Steady state operations for the inverter control signals are shown in Figure 13; the sinusoidal reference with a higher frequency clearly illustrates the PWM operation and the control signals of $S_{a}, S_{b}$, and $S_{c}$ of the multilevel inverter.

Some other waveforms for the converter at steady state are shown in Figure 14, which are related to the output. Two control signals, the output current and the sinusoidal reference, generate a multilevel output current. The current THD obtained in this test is lower than 5\%, actually in order to be precise is $2.7 \%$.

Experimental results under changing conditions are illustrated in Figures 15 and 16. PV panel power variations are illustrated in Figure 15, where the two evaluated conditions are shown in Table 2. This test was made under the same 


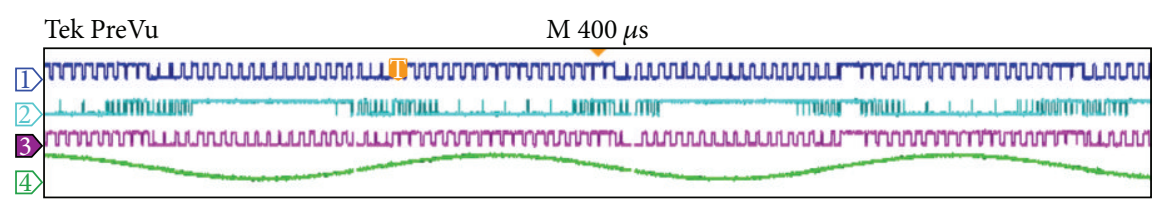

(a)

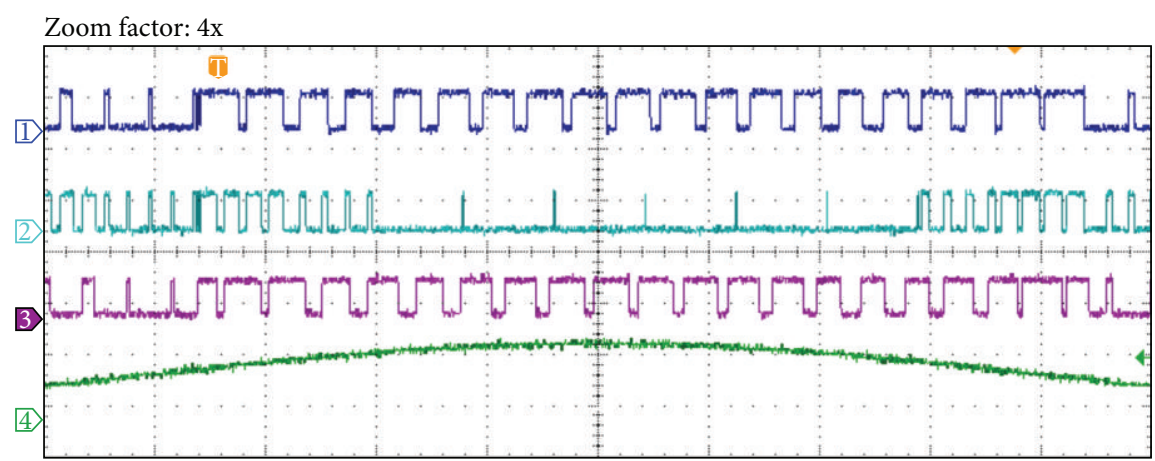

(b)

FIGURE 13: Control signals of the switches and sinusoidal reference. Top to bottom: control signal $S_{1}, S_{3}$, and $S_{2}$, respectively, (5 V/div each) and sinusoidal reference ( $2 \mathrm{~V} /$ div each). Time: $400 \mu \mathrm{s} / \mathrm{div}$; zoom time $100 \mu \mathrm{s} / \mathrm{div}$.

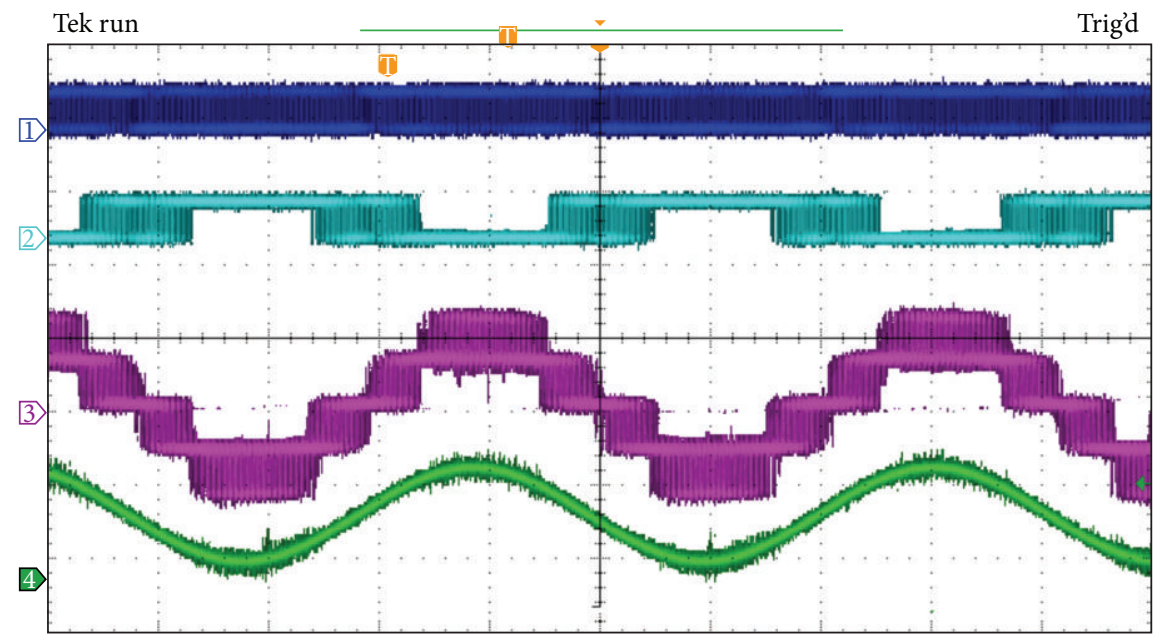

Figure 14: Operation of the system under a steady state. Top to bottom: control signals $S_{1}$ and $S_{3}$, respectively, (5V/div each), output current ( $2 \mathrm{~A} / \mathrm{div})$, sinusoidal reference ( $2 \mathrm{~V} / \mathrm{div})$. Time $4 \mathrm{~ms} / \mathrm{div}$.

irradiance condition; five or four PV panels are connected in series for each case; indeed one panel of the five is in short circuit to have four panels in operation. AC mains voltage, output current, sinusoidal reference and PV panel voltage are also shown. It is easily seen that delivered power to the AC mains changes according to power variation of the PV panel.

System operation under grid disconnection is illustrated in Figure 16; the capacitor $C_{o}$ voltage, the filtered output current, the capacitor $C_{r}$ voltage and the control signal which detects the grid disconnection (overvoltage for this capacitor) are included. It should be noticed that during AC mains disconnection not only the voltage of $C_{r}$ increases, but also
TABLe 2: Conditions of the PV panel.

\begin{tabular}{lc}
\hline First condition & Second condition \\
\hline$V_{\mathrm{mp}}=60 \mathrm{~V}$ & $V_{\mathrm{mp}}=80 \mathrm{~V}$ \\
$V_{\mathrm{oc}}=75 \mathrm{~V}$ & $V_{\mathrm{oc}}=100 \mathrm{~V}$ \\
$I_{\mathrm{mp}}=0.5 \mathrm{~A}$ & $I_{\mathrm{mp}}=0.5 \mathrm{~A}$ \\
$I_{\mathrm{sc}}=0.7 \mathrm{~A}$ & $I_{\mathrm{sc}}=0.7 \mathrm{~A}$ \\
\hline
\end{tabular}

the output voltage suddenly reaches the AC mains voltage peak due to the conduction of diode $D_{1}$ and connection with the capacitor $C_{r}$. When voltage for the capacitor $C_{r}$ reaches the established value to determine grid disconnection, the 


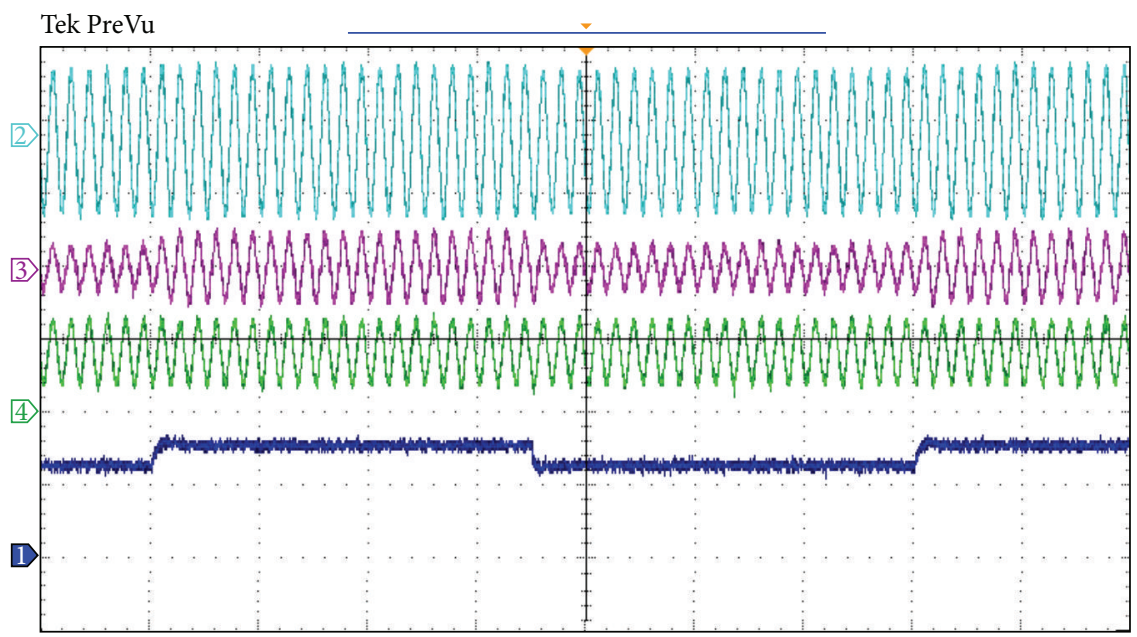

FIgURE 15: Operation of the system under PV perturbation. Top to bottom: Ac mains voltage (100 V/div), Output current (1 A/div), Sinusoidal reference (2 V/div), PV panel voltage (50 V/div). Time $100 \mathrm{~ms} /$ div.

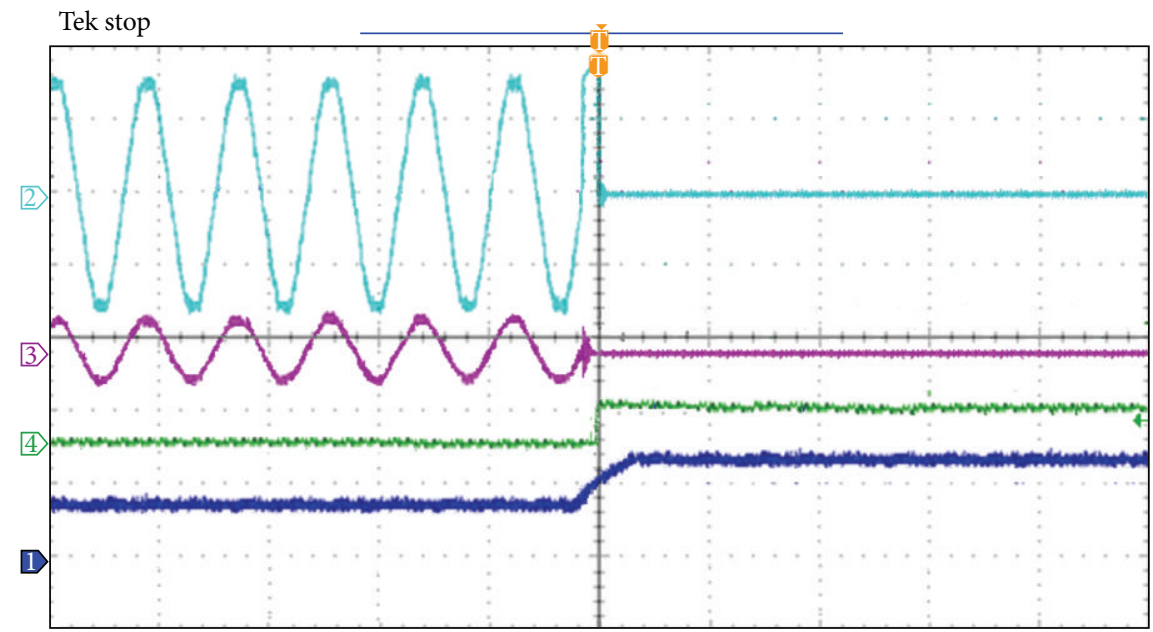

FIGURE 16: Operation of the system under grid disconnection. Top to down: Capacitor $C_{o}$ voltage (100 V/div), Output current (1 A/div), grid disconnection detector by using overvoltage detector ( $5 \mathrm{~V} / \mathrm{div})$, and Capacitor voltage $C_{r}(100 \mathrm{~V} / \mathrm{div})$. Time $20 \mathrm{~ms} / \mathrm{div}$.

detector defines when the switch $S_{\text {in }}$ is turned off; however, the capacitor $C_{r}$ will increase its voltage until the input inductors $L_{1}$ and $L_{2}$ are completely discharged. Protection circuit operates the system safely.

\section{Conclusions}

This paper presents a grid-connected multilevel current source inverter. It is proposed not only to operate under low PV panel voltage, due to the boosting capability of the CSI topology employed, but also a low THD at low switching frequency is obtained due to the multilevel operation.

The proposed converter considers a grid disconnection circuit for security reasons. When considering current sources, disconnection may damage not only some circuits connected to it but also the whole system; therefore it is necessary to include a method for alleviating this issue.
Operation, analysis, and implementation were exposed, and finally simulation and experimental results were discussed.

\section{References}

[1] J. M. Carrasco, L. G. Franquelo, J. T. Bialasiewicz et al., "Powerelectronic systems for the grid integration of renewable energy sources: a survey," IEEE Transactions on Industrial Electronics, vol. 53, no. 4, pp. 1002-1016, 2006.

[2] N. Femia, G. Petrone, G. Spagnuolo, and M. Vitelli, "A technique for improving P\&O MPPT performances of double-stage gridconnected photovoltaic systems," IEEE Transactions on Industrial Electronics, vol. 56, no. 11, pp. 4473-4482, 2009.

[3] I. S. Kim, M. B. Kim, and M. J. Youn, "New maximum power point tracker using sliding-mode observer for estimation of solar array current in the grid-connected photovoltaic system," IEEE Transactions on Industrial Electronics, vol. 53, no. 4, pp. 1027-1035, 2006 
[4] J. M. Kwon, K. H. Nam, and B. H. Kwon, "Photovoltaic power conditioning system with line connection," IEEE Transactions on Industrial Electronics, vol. 53, no. 4, pp. 1048-1054, 2006.

[5] J. H. Park, J. Y. Ahn, B. H. Cho, and G. J. Yu, "Dual-modulebased maximum power point tracking control of photovoltaic systems," IEEE Transactions on Industrial Electronics, vol. 53, no. 4, pp. 1036-1047, 2006.

[6] N. Onat, "Recent developments in maximum power point tracking technologies for photovoltaic systems," International Journal of Photoenergy, vol. 2010, Article ID 245316, 11 pages, 2010.

[7] R. Leyva, C. Olalla, H. Zazo et al., "MPPT based on sinusoidal extremum-seeking control in PV generation," International Journal of Photoenergy, vol. 2012, Article ID 672765, 7 pages, 2012.

[8] P. Bhatnagarn and R. K. Nema, "Maximum power point tracking control techniques: state-of-the-art in photovoltaic applications," Renewable and Sustainable Energy Reviews, vol. 23, pp. 224-241, 2013.

[9] H. Ertl, J. W. Kolar, and F. C. Zach, "A novel multicell DC-AC converter for applications in renewable energy systems," IEEE Transactions on Industrial Electronics, vol. 49, no. 5, pp. 10481057, 2002.

[10] J. Selvaraj and N. A. Rahim, "Multilevel inverter for gridconnected PV system employing digital PI controller," IEEE Transactions on Industrial Electronics, vol. 56, no. 1, pp. 149-158, 2009.

[11] C. L. Shen and J. C. Su, "Grid-connection half-bridge PV inverter system for power flow controlling and active power filtering," International Journal of Photoenergy, vol. 2012, Article ID 760791, 8 pages, 2012.

[12] S. Busquets-Monge, J. Rocabert, P. Rodríguez, S. Alepuz, and J. Bordonau, "Multilevel diode-clamped converter for photovoltaic generators with independent voltage control of each solar array," IEEE Transactions on Industrial Electronics, vol. 55, no. 7, pp. 2713-2723, 2008.

[13] S. Sladic, S. Skok, and D. Nedeljkovic, "Efficiency considerations and application limits of single-phase active power filter with converters for photoenergy applications," International Journal of Photoenergy, vol. 2011, Article ID 643912, 8 pages, 2011.

[14] C. T. Tsai and S. H. Chen, "PV power-generation system with a phase-shift PWM technique for high step-up voltage applications," International Journal of Photoenergy, vol. 2012, Article ID 838231, 11 pages, 2012.

[15] K. Kobayashi, H. Matsuo, and Y. Sekine, "Novel solar-cell power supply system using a multiple-input DC-DC converter," IEEE Transactions on Industrial Electronics, vol. 53, no. 1, pp. 281-286, 2006.

[16] G. R. Walker and P. C. Sernia, "Cascaded DC-DC converter connection of photovoltaic modules," IEEE Transactions on Power Electronics, vol. 19, no. 4, pp. 1130-1139, 2004.

[17] Y. M. Chen, Y. C. Liu, S. C. Hung, and C. S. Cheng, "Multi-input inverter for grid-connected hybrid PV/wind power system," IEEE Transactions on Power Electronics, vol. 22, no. 3, pp. 10701077, 2007.

[18] Y. M. Chen, Y. C. Liu, and S. H. Lin, "Double-input PWM DC/DC converter for high-/low-voltage sources," IEEE Transactions on Industrial Electronics, vol. 53, no. 5, pp. 1538-1545, 2006.

[19] Y. M. Chen, Y. C. Liu, and F. Y. Wu, "Multi-input dc/dc converter based on the multiwinding transformer for renewable energy applications," IEEE Transactions on Industry Applications, vol. 38, no. 4, pp. 1096-1104, 2002.

[20] T. T. Chow, G. N. Tiwari, and C. Menezo, "Hybrid solar: a review on photovoltaic and thermal power integration," International Journal of Photoenergy, vol. 2012, Article ID 307287, 17 pages, 2012.

[21] J. S. Silva, A. R. Cardoso, and A. Beluco, "Consequences of reducing the cost of PV modules on a PV wind diesel hybrid system with limited sizing components," International Journal of Photoenergy, vol. 2012, Article ID 384153, 7 pages, 2012.

[22] C. C. Chan and Y. M. Chang, "Current source inverter with energy clamp circuit and controlling method therefore having relatively better effectiveness," US patent No. US2007/0230220A1.

[23] P. G. Barbosa, H. A. C. Braga, M. C. B. Rodrigues, and E. C. Teixeira, "Boost current multilevel inverter and its application on single-phase grid-connected photovoltaic systems," IEEE Transactions on Power Electronics, vol. 21, no. 4, pp. 1116-1124, 2006.

[24] D. Amorndechaphon, S. Premrudeepreechacharn, K. Higuchi, and X. Roboam, "Modified grid-connected CSI for hybrid $\mathrm{PV} /$ wind power generation system," International Journal of Photoenergy, vol. 2012, Article ID 381016, 12 pages, 2012.

[25] P. P. Dash and M. Kazerani, "Dynamic modeling and performance analysis of a grid-connected current-source inverterbased photovoltaic system," IEEE Transactions on Sustainable Energy, vol. 2, no. 4, pp. 443-450, 2011.

[26] F. L. M. Antunes, H. A. C. Braga, and I. Barbi, "Application of a generalized current multilevel cell to current-source inverters," IEEE Transactions on Industrial Electronics, vol. 46, no. 1, pp. 3138, 1999.

[27] N. Vázquez, H. López, C. Hernández, E. Vázquez, R. Osorio, and J. Arau, "A different multilevel current source inverter," IEEE Transactions on Industrial Electronics, vol. 57, no. 8, pp. 2623-2632, 2010. 

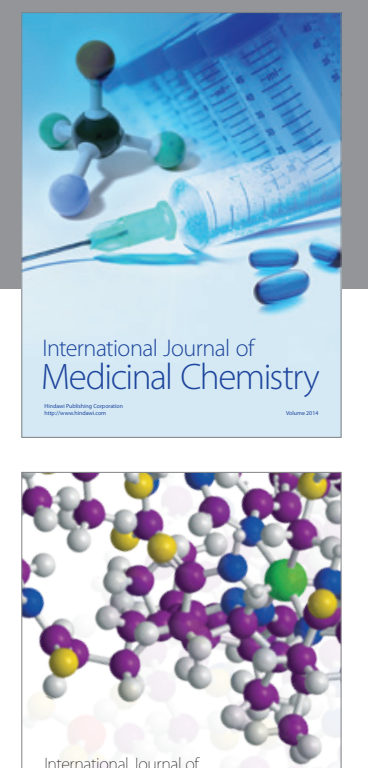

\section{Carbohydrate} Chemistry

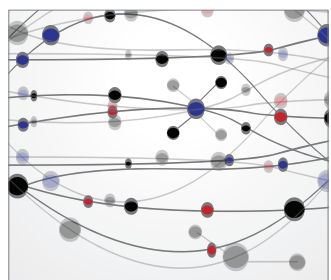

The Scientific World Journal
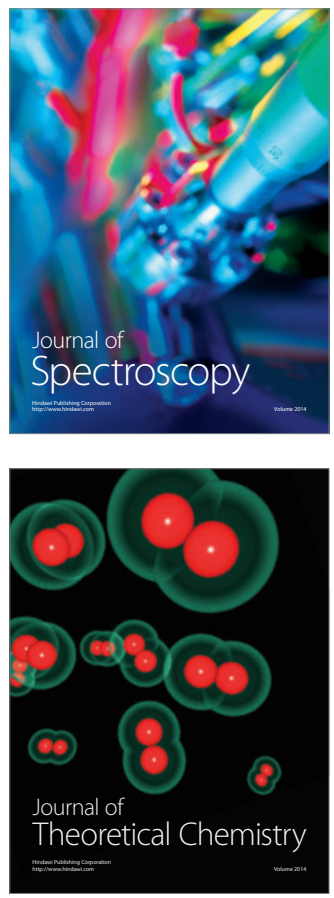
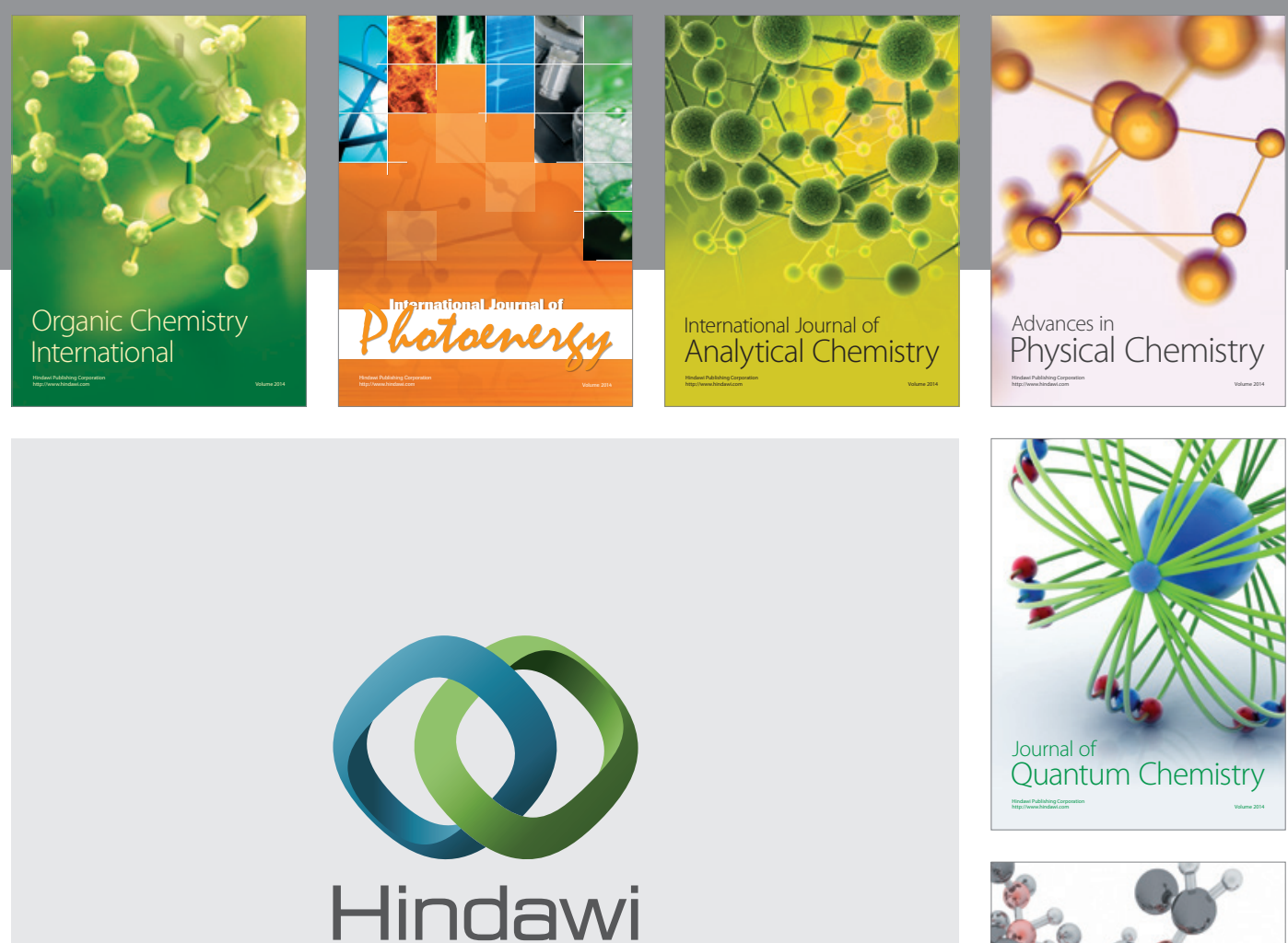

Submit your manuscripts at

http://www.hindawi.com

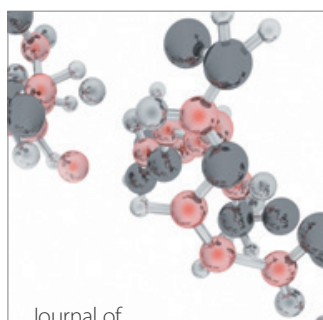

Analytical Methods

in Chemistry

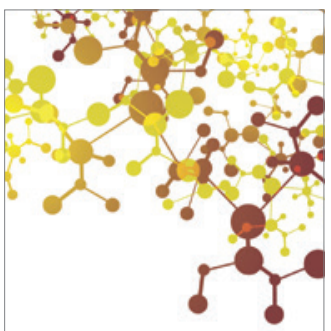

Journal of

Applied Chemistry

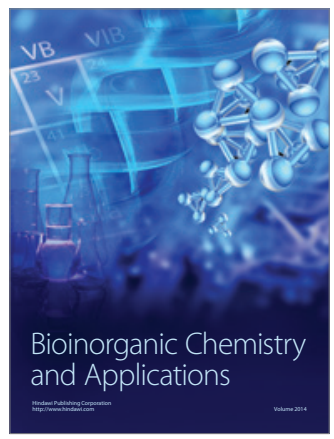

Inorganic Chemistry
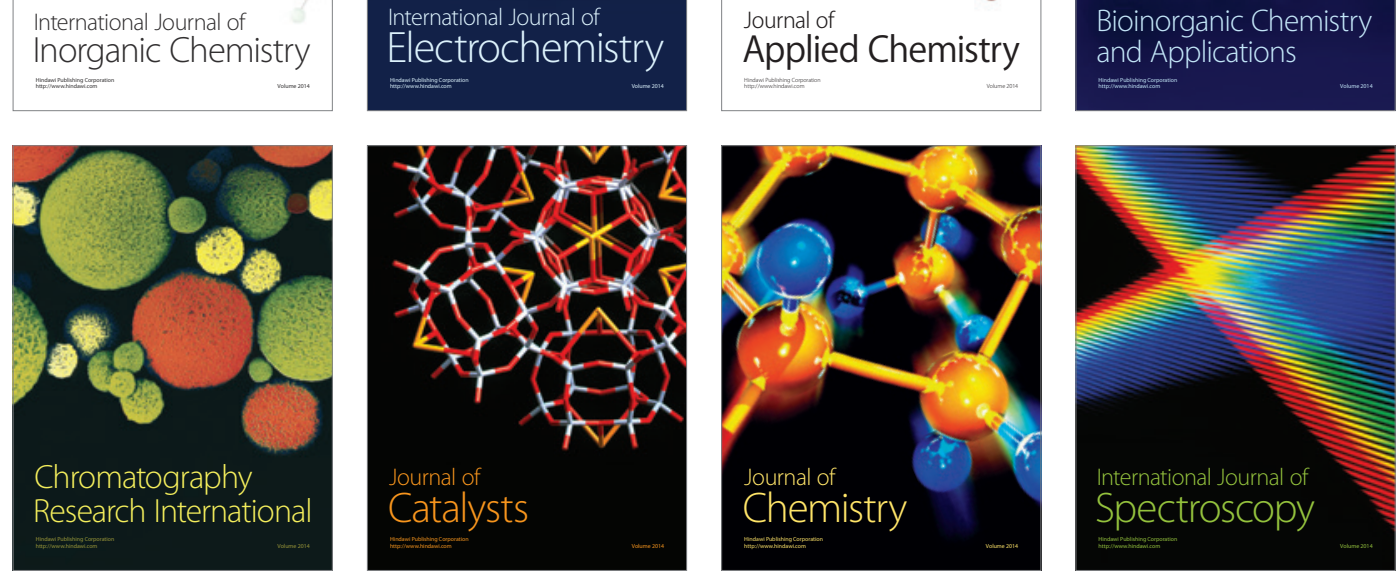